\title{
Thyroxine Turnover and Transport in Laennec's Cirrhosis of the Liver*
}

\author{
Mitsuo Inada $\ddagger$ and Kenneth Sterling $\S$ \\ (From the Medical Service, Bromx Veterans Administration Hospital and The Department of \\ Pathology, Columbia University College of Physicians and Surgeons, \\ New York)
}

\begin{abstract}
Summary. Studies of the metabolism of thyroxine in 14 cases of cirrhosis revealed a variety of deviations from normal. In addition to radiothyroxine turnover studies, determinations were made of the free thyroxine fractions and free thyroxine iodine concentrations in serum (magnesium precipitation method) as well as the maximal binding capacities of thyroxine-binding alpha globulin (TBG) and thyroxine-binding prealbumin (TBPA) by reverse flow paper electrophoresis in a glycine acetate system at $\mathrm{pH}$ 8.6.

All cases of cirrhosis exhibited diminutions in TBPA capacities but their TBG capacities showed a wide scatter $(13.4$ to $41.6 \mu \mathrm{g} / 100 \mathrm{ml})$. The free thyroxine fraction was quite variable, with distinct elevations in nine of the 17 sera.

The binding proteins appeared to be determinants of the free thyroxine fraction, which in turn, appeared to be a direct determinant of the half-time of turnover. These inferences did not exclude other possible factors including diminished hepatic uptake and metabolism of the hormone in liver disease.

Despite considerable alterations in biological half-times, free thyroxine values, and binding proteins, it was remarkable that the absolute hormone disposal was normal in all 14 patients with cirrhosis.
\end{abstract}

\section{Introduction}

The abnormalities of ${ }^{131}$ I-labeled thyroxine metabolism in diseases of the liver have been reported by several investigators (1-3). However, these abnormalities have not been reported in detail in relation to thyroxine-binding proteins and free thyroxine values in serum.

The present paper indicates that patients with hepatic cirrhosis may show various abnormalities of thyroxine metabolism, of thyroxine-binding proteins, and of free thyroxine values in serum.

\footnotetext{
* Submitted for publication April 20, 1966; accepted May 18, 1967.

Supported in part by grants AM-10739-01 and AM10739-02 from the U. S. Public Health Service and by grant P-226 from the American Cancer Society.

$¥$ Visiting investigator from the Department of Internal Medicine, Kyoto University School of Medicine, Kyoto, Japan.

$\S$ Address requests for reprints to Dr. Kenneth Sterling, Veterans Administration Hospital, 130 West Kingsbridge Road, Bronx, N. Y. 10468.
}

\section{Methods}

Clinical material. All subjects selected for this study were men hospitalized on the Medical Service of the Bronx Veterans Administration Hospital.

Hospital controls. Eight patients with no evidence of hepatic or endocrine disease were studied as "hospital controls." Their clinical diagnoses and liver function tests are shown in Table I.

Hepatic cirrhosis. 14 patients with hepatic cirrhosis associated with alcoholism were studied. Two patients (TR and JA) were studied more than once at intervals of approximately 3 months during the course of their hospitalization. All patients either exhibited or had previously shown enlargement of the liver, jaundice, ascites, edema, and esophageal varices with melena or hematemesis or both. In eight patients the diagnosis was confirmed histologically by biopsy with the Menghini needle. The histological diagnoses are shown in Table I. The cases were divided into two groups, "moderate" and "advanced" cirrhosis. This differentiation was established originally on the basis of the severity of the clinical picture; it was found that all "moderate" cases had cephalin flocculation tests of +2 or less, whereas eight of the nine "advanced" cases had +4 , and one had +3 . 


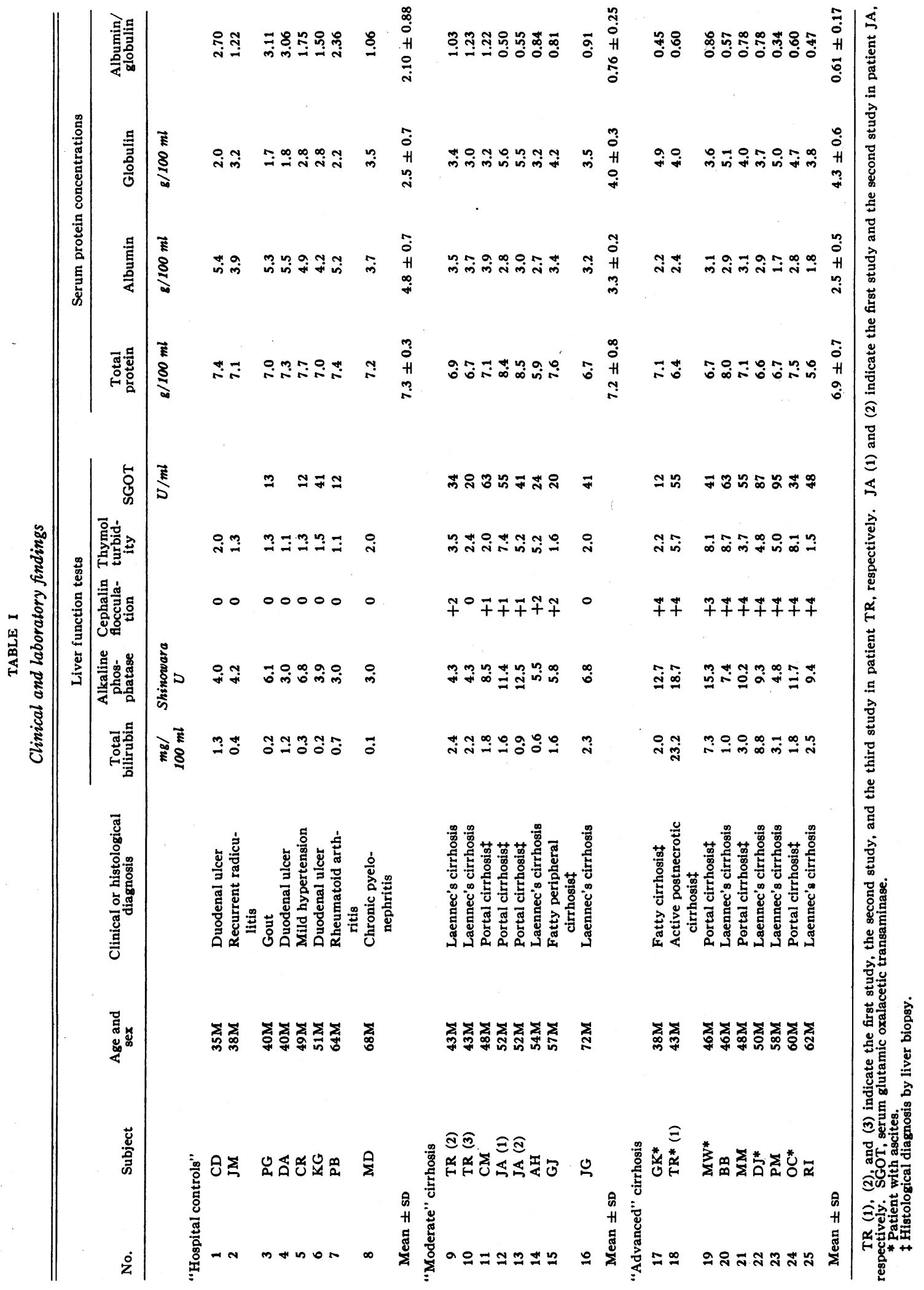


The other tests were generally consistent with this division (Table I). None of the patients had goiters or other stigmata of thyroid disease.

Liver function tests. Liver function tests were done on all patients at least twice during the course of the studies, in addition to numerous tests done before and after the studies as well. The serum concentrations of total protein (biuret), direct and total bilirubin, alkaline phosphatase (Shinowara units), serum glutamic oxalacetic transaminase (SGOT), and cephalin flocculation and thymol turbidity tests were determined by standard methods. The serum concentrations of albumin and globulin were estimated from the total protein, and the proportion of albumin and globulin after paper electrophoresis of serum with barbital buffer at $\mathrm{pH} 8.6$, and quantitation of the pattern by Spinco Analytrol. Additional tests not given in Table I included serum glutamic pyruvic transaminase (SGPT), serum cholesterol, prothrombin time, and bromsulfalein retention.

${ }^{131} I$-labeled L-thyroxine turnover study. ${ }^{151}$ I-labeled L-thyroxine in propylene glycol solution was obtained from a commercial source ${ }^{1}$ with $0.2 \%$ cysteine added by the supplier for stabilization. Shipments were tested for purity by descending paper chromatography with the $n$-butanol-dioxane-ammonia system. The radiothyroxine was free of appreciable radioactive contaminants other than $1-5 \%$ iodide. The precise per cent of radioactivity due to iodide- ${ }^{121} \mathrm{I}$ was determined by paper electrophoresis in a glycine acetate system (4) for $90 \mathrm{~min}$. The radiothyroxine was administered within a few days after receipt. $\quad 35-60 \mu \mathrm{c}$ of radiothyroxine $(0.8-1.6 \mu \mathrm{g})$ diluted in $0.125 \mathrm{~g}$ per $100 \mathrm{ml}$ albumin in normal saline solution was injected into the antecubital vein. Venous blood was taken from the patient's opposite arm at the following intervals after the injection of the radiothyroxine: 10 $\min , 24 \mathrm{hr}$, and subsequently on alternate days for 15-21 days. The radioactivity of heparinized plasma or serum was determined by counting $5 \mathrm{ml}$ in a Packard AutoGamma well-type scintillation counter for $10 \mathrm{~min}$, and was converted into radioactivity per liter of serum as per cent of the administered dose. Correction for physical decay was obviated by comparing the radioactivity of all samples to that of a suitably diluted aliquot of the administered dose.

Method of analysis. Semilogarithmic plots were made of the disappearance curves of the radioactivity of plasma or serum. The thyroxine distribution space (TDS), the thyroxine half-time $\left(t_{i}\right)$, the fraction of extrathyroidal organic iodine turnover each day $(k)$, the extrathyroidal organic iodine (EOI) pool, and the thyroxine iodine removal rate (TIRR) were obtained in each study by the extrapolation method, which was reported previously (510). Moreover, in the present paper, the extravascular thyroxine distribution space (TDSe) was calculated as follows :

$$
\mathrm{TDSe}=\mathrm{TDS}-\mathrm{TDSi},
$$

where TDSi was the intravascular thyroxine distribution space obtained from the quotient, total injected radio-

\footnotetext{
1 Abbott Laboratories, North Chicago, Ill.
}

activity (100\%) divided by plasma ${ }^{131} \mathrm{I}$ concentration (per cent per liter) $10 \mathrm{~min}$ after injection of radiothyroxine. The percentage in the extravascular compartment ("extravascular per cent") was calculated from the ratio of TDSe to TDS. In all subjects the EOI and TIRR values were adjusted to $1.73 \mathrm{~m}^{2}$ body surface area. It was previously demonstrated $(6,9,10)$ that radioactivity in serum consisted mainly of radiothyroxine in such studies and that the administration of iodide had no appreciable effect on the disappearance curve except in thyrotoxicosis.

Paper electrophoretic study. The maximal binding capacities of thyroxine-binding alpha globulin (TBG) and thyroxine-binding prealbumin (TBPA) were determined in duplicate by reverse flow paper electrophoresis (11) with a glycine acetate system at $\mathrm{pH} 8.6$ (4), using the Spinco-Durrum apparatus. The details of the procedure are described by Inada and Sterling (12).

Determination of free thyroxine in serum. Free thyroxine fractions in serum were determined by the magnesium precipitation method in duplicate or triplicate as described by Sterling and Brenner (13). The free thyroxine iodine concentrations in $\mathrm{m} \mu \mathrm{g}$ per $100 \mathrm{ml}$ were the products of free thyroxine percentages and proteinbound iodine (PBI) or thyroxine iodine values.

In all sera PBI values and, where indicated, measurements of thyroxine iodine by column as well, were obtained from a commercial laboratory. ${ }^{2}$

All maximal binding capacities of TBG and TBPA, free thyroxine fractions, and PBI values were determined in serum drawn before injection of radiothyroxine, as well as that taken on the last day of the thyroxine turnover study. The averages of these values are shown in Table II. In most instances the initial and final PBI or thyroxine iodine values agreed within $1 \mu \mathrm{g}$ per $100 \mathrm{ml}$. Where a discrepancy existed, additional values were obtained on sera or plasmas taken during the course of the studies. In no case was there any evidence of a systematic change suggesting alteration of the "steady state" during the course of the turnover studies that usually approximated $3 \mathrm{wk}$.

\section{Results}

The results, summarized in Table II, showed a wide variety of abnormalities.

Abnormally short biological half-times (2.3-5.5 days) occurred in four subjects, and two showed very long half-times of 11.0 and 14.0 days, associated with elevated TBG capacities of 30.1 and $41.6 \mu \mathrm{g}$ per $100 \mathrm{ml}^{3}{ }^{3}$ Despite variability of half-

\footnotetext{
2 Bio-Science Laboratories, Van Nuys, Calif.

${ }^{3}$ It is of interest that the half-time $\left(t_{1}\right)$ of the "hospital controls" ranged from 7.3-8.0 days (mean $\pm \mathrm{SD}=7.7$ \pm 0.3 days), values appreciably greater than those of the healthy young male volunteers previously reported $(6,7)$. The half-times of $6.7 \pm 0.7$ and $7.2 \pm 0.4$ days previously observed differ significantly from the present "hospital
} 


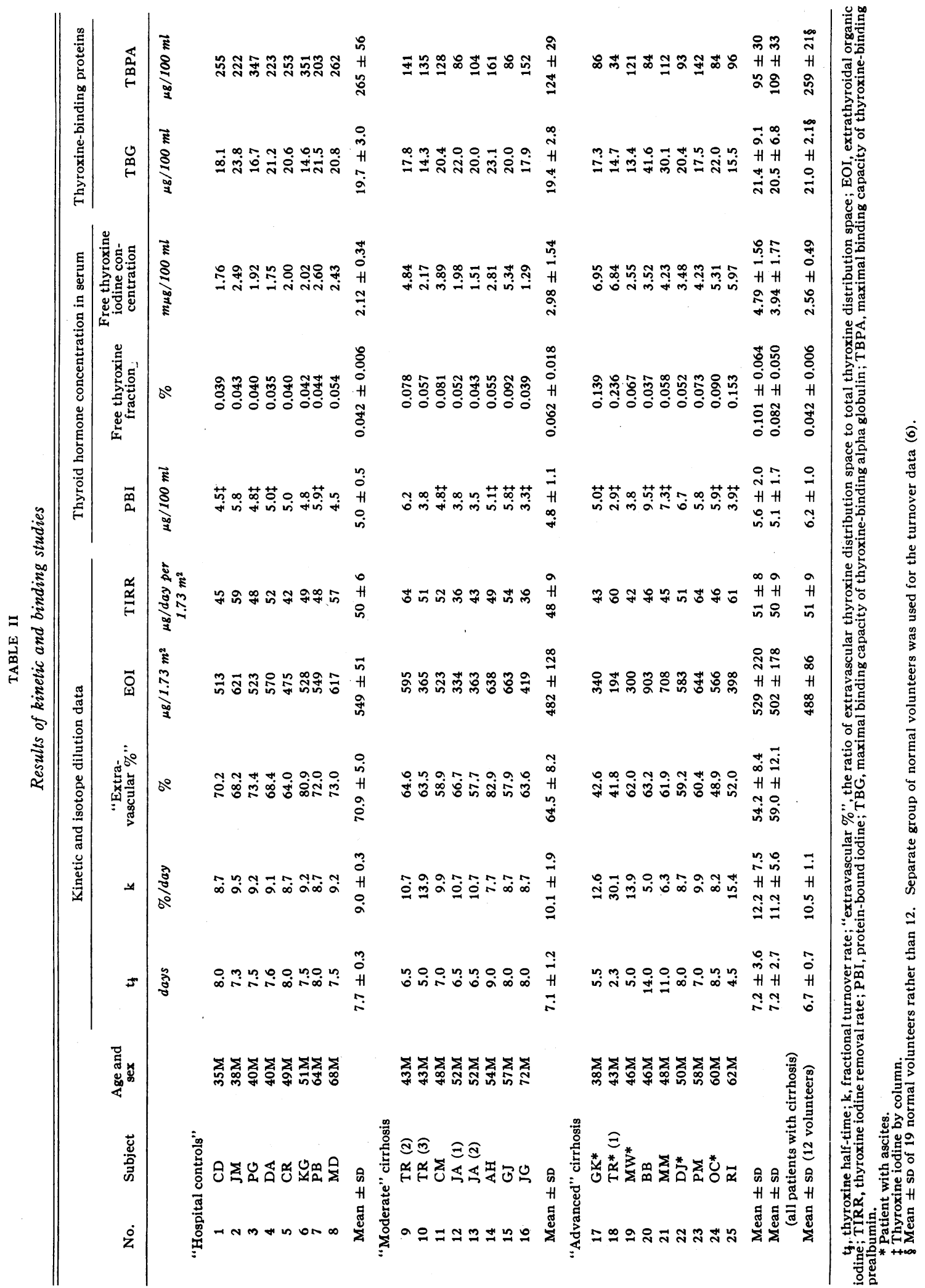


times, the absolute thyroxine iodine removal rates were all normal, regardless of the severity of the disease (Figure 1, p >0.1). This was explainable by the direct relationship observed between the extrathyroidal organic iodine (EOI) pool and the half-time (Figure 2 ) with correlation coefficient of $+0.80, \mathrm{p}<0.001$. These findings illustrated maintenance of normal hormone disposal despite abnormalities in the serum proteins (Table I) including the thyroxine carriers (Table II).

The extrathyroidal organic iodine (EOI) pools were variable, but the percentage in the extravascular compartment ("extravascular per cent" in Table II) was lower in cirrhosis, $59.0 \pm 12.1 \%$, as compared with $70.9 \pm 5.0 \%$ in the control group, $\mathrm{p}<0.025$. Moreover, the five patients with ascites showed a still lower "extravascular per cent," $50.1 \pm 8.6 \%, \mathrm{p}<0.001$ versus controls.

All sera from patients with cirrhosis had diminished TBPA binding capacities, in general parallel to the reductions in serum albumin concentration $(r=+0.77$ for cirrhosis and controls,

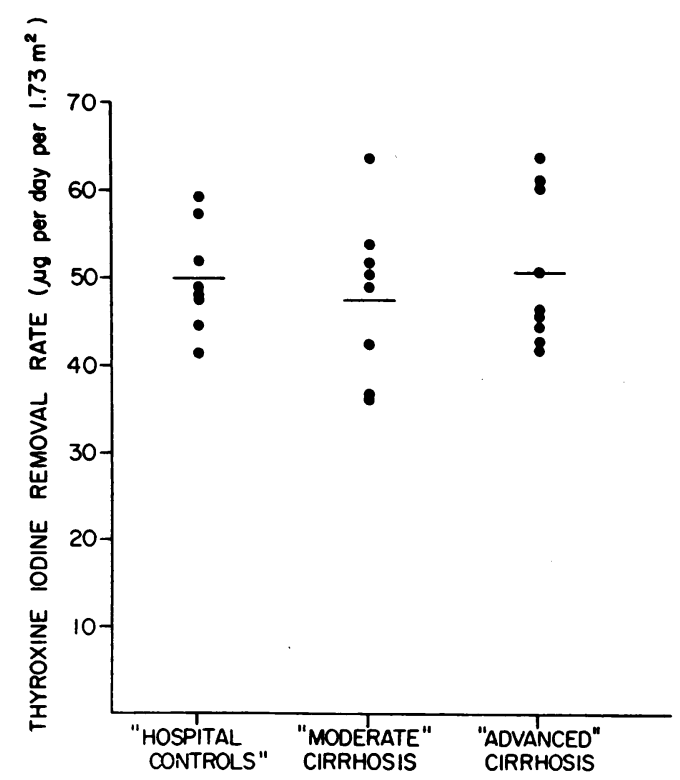

Fig. 1. Thyroxine iodine removal rates. Mean values are indicated by horizontal solid lines.

controls" ( $p<0.01)$. The difference may be due in part to the greater age of the present control group. Gregerman, Gaffney, and Shock have shown clearly that thyroxine turnover is prolonged as a function of aging (14), and this has been confirmed extensively (15).

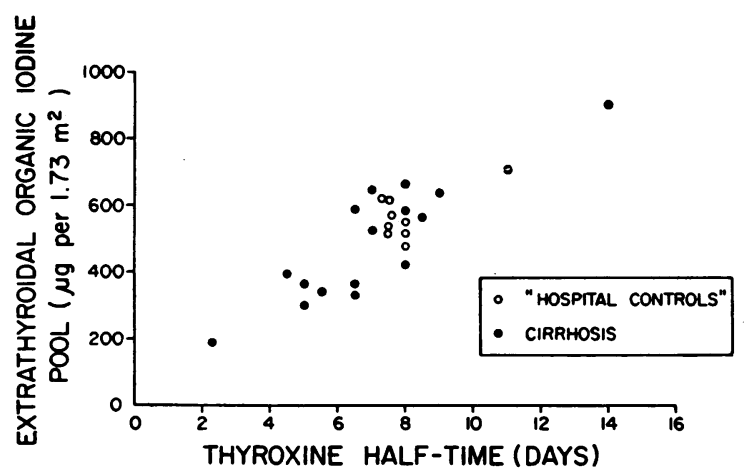

Fig. 2. Relation BetWeEn extrathyroidal ORGanic IODINE (EOI) POOL AND THYROXINE haLF-TIME. Correlation coefficient is +0.80 in patients with cirrhosis $(p<$ 0.001 ).

p < 0.001). However, TBG showed marked variation, including two elevated and four diminished values. ${ }^{4}$ The free thyroxine fraction was quite variable, with distinct elevations in nine of the 17 sera. The free thyroxine iodine concentrations as well as the PBI values showed a wide scatter from below to above the normal range (Table II).

In general, more pronounced deviations from the normal range occurred in "advanced" than in "moderate" cirrhosis, although these differences were not statistically significant either in kinetic studies or in thyroxine binding studies $(0.1>\mathrm{p}>$ $0.05)$.

\section{Discussion}

Despite alterations in biological half-times, binding proteins, and free thyroxine values, it was remarkable that the hormone disposal was normal in all 17 studies of 14 patients with cirrhosis. The present findings do not account completely for this regulation, nor for many other changes observed. Nevertheless, certain relationships were found and require consideration.

Diminished TBPA capacity, found in all of the present sera, has been shown to be associated with reduced concentration of this protein due to impaired synthesis in acute injury and in chronic illness including hepatic cirrhosis $(17,18)$. While

\footnotetext{
4 In a large series of normal males, Braverman, Dawber, and Ingbar (16) observed small but consistent changes in TBG and TBPA capacities related to age. The magnitude was smaller than the alterations reported in the present paper.
} 


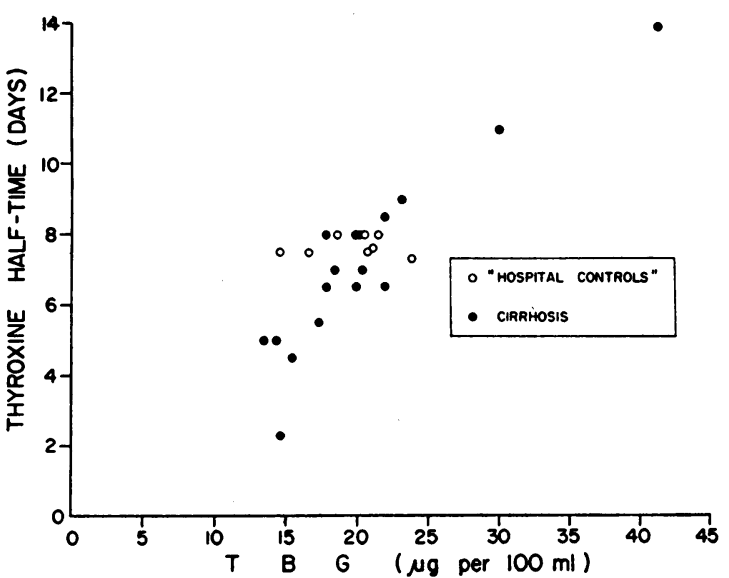

Fig. 3. Relation Between thyroxine halF-time AND TBG. TBG signifies maximal binding capacity of thyroxine-binding alpha globulin. Correlation coefficient is +0.92 in patients with cirrhosis $(\mathrm{p}<0.001)$.

such evidence is not available regarding TBG, similar phenomena would seem reasonable.

In this study, the biological half-time showed good correlation with TBG capacity (Figure 3, $r=+0.92, \mathrm{p}<0.001$ ) but not with TBPA capacity $(r=+0.39, \mathrm{p}>0.1)$. Since the TBPA capacities were variably reduced in all 17 sera studied, it is not unexpected that TBG could become the limiting factor. For example, No. 20, $\mathrm{BB}$, with markedly elevated TBG of $41.6 \mu \mathrm{g}$ per $100 \mathrm{ml}$ had a prolonged half-time of 14.0 days, and No. 21, MM, with TBG of 30.1 had an 11.0 day half-time, despite reduced TBPA in both instances. On the other hand, the importance of TBPA is suggested by the serial studies on No. 18 TR (1), No. 9 TR (2), and No. 10 TR (3) with rise of the half-time from 2.3-6.5 days together with rise of TBPA capacity from the very low value of 34-141 $\mu \mathrm{g}$ per $100 \mathrm{ml}$ whereas TBG rose only slightly $(14.7-17.8 \mu \mathrm{g} / 100 \mathrm{ml})$ with clinical improvement. The effect of TBG is shown by its subsequent fall to $14.3 \mu \mathrm{g}$ per $100 \mathrm{ml}$, with the half-time now somewhat shorter (5.0 days) despite maintenance of essentially unchanged TBPA.

The suggestion that TBPA as well as TBG may be a determinant of the half-time is compatible with statistical analysis which shows excellent correlation of half-time with the two variables, TBG and TBPA $(r=+0.95, \mathrm{p}<0.001)$.

This inference is consistent with previous reports concerning the role of the binding proteins in the regulation of the peripheral metabolism of thyroxine (19-21). In addition, both TBG and TBPA have been shown to be important factors in the proportion of unbound hormone $(13,22$ 25 ).

The binding proteins, therefore, may be considered determinants of the free thyroxine fraction, which in turn, is believed to be a direct determinant of the half-time of turnover.

The inverse relation between half-time and free thyroxine fraction, illustrated in Figure 4, had a correlation coefficient of $-0.69, \mathrm{p}<0.01$.

In the present data, free thyroxine fraction was found inversely related to the maximal binding capacities of both binding proteins. The free thyroxine fraction bore a significant inverse relation to the two variables, TBG and TBPA $(r=-0.63$, $\mathrm{p}<0.01)$. As discussed below, additional factors may be operative in liver disease.

The findings of Hollander and co-workers (26) suggest that elevation of free fatty acids may influence the free thyroxine fraction. Since free fatty acids are albumin-bound, hypoalbuminemia itself may conceivably permit nonprotein-bound free fatty acids to cause additional elevation of the free thyroxine fraction. The free thyroxine fraction showed a more pronounced inverse correlation of -0.79 against albumin, TBG, and TBPA as three variables $(p<0.001)$, than against the latter two.

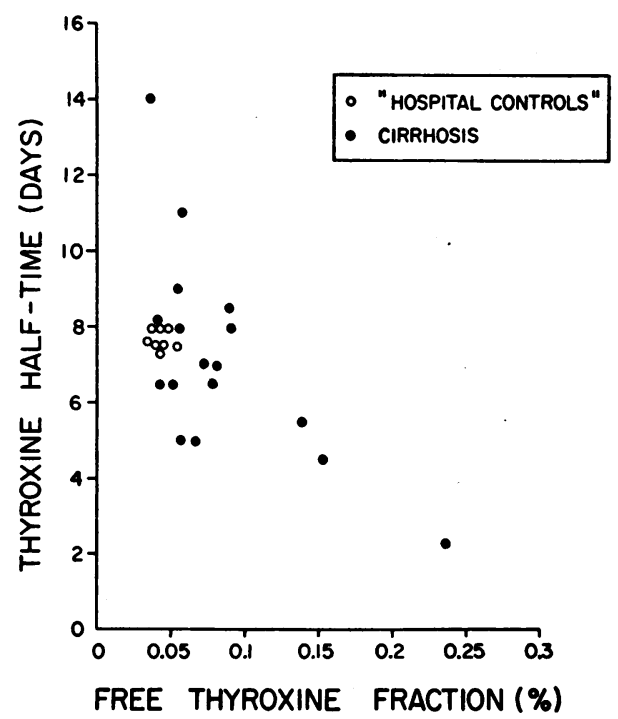

Fig. 4. Relation BetWeEN THYROXINE HALF-TIME AND FREE THYROXINE FRACTION. Correlation coefficient is -0.69 in patients with cirrhosis $(p<0.01)$. 
With regard to radiothyroxine distribution and turnover, it may be supposed that impaired hepatic uptake and removal of thyroxine might have some influence. The appreciable accumulation of radiothyroxine in the liver after intravenous injection has previously been found markedly diminished in cirrhosis and hepatitis $(8,9)$. Recent acute distribution studies by different techniques have indicated diminished hepatic uptake in liver disease (3, $27,28)$. Such factors may well contribute to the significantly reduced "extravascular per cent" in the present study, especially pronounced in advanced cirrhosis with ascites. Systematic errors of the extrapolation methodology employed in this study might be expected to overestimate rather than underestimate total and extravascular pools, especially in the presence of ascites. Therefore, the diminished "extravascular per cent" in cirrhosis is probably a real phenomenon which requires more complete elucidation.

All the kinetic data ( $t_{\frac{1}{2}}$, "extravascular per cent," EOI, and TIRR) differed less from the control group than the binding data (free thyroxine fraction, free thyroxine iodine concentration, TBG, and TBPA) according to analysis of variance $(p<0.001)$. Limitation of hepatic removal could acount for relatively less deviation from normal in the kinetic data than might have been anticipated from abnormalities of binding proteins and free thyroxine values. The findings of the present study provide an illustration of maintenance of the constancy of absolute hormone disposal rate, irrespective of alterations in thyroxine metabolism, thyroxine-binding proteins and serum thyroxine concentration.

\section{Acknowledgments}

The authors wish to express gratitude for the valuable technical assistance of Mr. Milton A. Brenner.

\section{References}

1. Vannotti, A., and T. Bérand. Functional relationships between the liver, the thyroxine-binding protein of serum, and the thyroid. J. clin. Endocr. 1959, 19, 466.

2. Lennon, E. J., N. H. Engbring, and W. W. Engstrom. Studies of the rate of disappearance of labeled thyroxine from the intravascular compartment. J. clin. Invest. 1961, 40, 996.

3. Cavalieri, R. R., and G. L. Searle. Role of the liver in the distribution of $\mathrm{I}^{181}$ thyroxine in man. The
Fifth International Thyroid Conference, Rome, $1965,336$.

4. Sterling, K., and M. Tabachnick. Paper electrophoretic demonstration of thyroxine-binding prealbumin fraction in serum. Endocrinology 1961, 68, 1073.

5. Sterling, K., J. C. Lashof, and E. B. Man. Disappearance from serum of $\mathrm{I}^{181}$-labeled $\mathrm{L}$-thyroxine and L-triiodothyronine in euthyroid subjects. J. clin. Invest. 1954, 33, 1031.

6. Sterling, K., and R. B. Chodos. Radiothyroxine turnover studies in myxedema, thyrotoxicosis and hypermetabolism without endocrine disease. $\mathrm{J}$. clin. Invest. 1956, 35, 806.

7. Kurland, G. S., J. G. Bustos, M. W. Hamolsky, and A. S. Freedberg. Studies in nonmyxedematous hypometabolism. II. Turnover of $\mathrm{I}^{132}$-labeled thyroxine after intravenous infusion. J. clin. Endocr. 1957, 17, 1365.

8. Friis, T. Thyroxine metabolism in man estimated by means of $\mathrm{I}^{131}$-labeled L-thyroxine. Acta endocr. 1958, 29, 587.

9. Inada, M. Clinical studies on metabolism of thyroid hormone. I. Studies on metabolism of $\mathrm{I}^{131}$-labeled L-thyroxine and age differences in normal subjects, in patients with untreated thyroid disorders, and in patients with liver disorders. Folia Endocr. Japonica. 1963, 39, 457.

10. Inada, M., K. Koshiyama, K. Torizuka, H. Akagi, and T. Miyake. Clinical studies on the metabolism of $\mathrm{I}^{181}$-labeled L-thyroxine. J. clin. Endocr. 1964, 24, 775.

11. Robbins, J. Reverse-flow zone electrophoresis. A method for determining the thyroxine-binding capacity of serum protein. Arch. Biochem. 1956, 63, 461.

12. Inada, M., and K. Sterling. Thyroxine transport in thyrotoxicosis and hypothyroidism. J. clin. Invest. 1967. In press.

13. Sterling, K., and M. A. Brenner. Free thyroxine in human serum: Simplified measurement with the aid of magnesium precipitation. J. clin. Invest. 1966, $45,153$.

14. Gregerman, R. I., G. W. Gaffney, and N. W. Shock. Thyroxine turnover in euthyroid man with special reference to changes with age. J. clin. Invest. 1962, 41, 2065.

15. Oddie, T. H., J. H. Meade, Jr., and D. A. Fisher. An analysis of published data on thyroxine turnover in human subjects. J. clin. Endocr. 1966, 26, 425.

16. Braverman, L. E., N. A. Dawber, and S. H. Ingbar. Observations concerning the binding of thyroid hormones in sera of normal subjects of varying ages. J. clin. Invest. 1966, 45, 1273.

17. Oppenheimer, J. H., M. I. Surks, G. Bernstein, and J. C. Smith. Metabolism of iodine-131-labeled thyroxine-binding prealbumin in man. Science 1965, 149, 748. 
18. Socolow, E. L., K. H. Woeber, R. H. Purdy, M. T. Holloway, and S. H. Ingbar. Preparation of $\mathrm{I}^{131}$ labeled human serum prealbumin and its metabolism in normal and sick patients. J. clin. Invest. $1965,44,1600$.

19. Ingbar, S. H., and N. Freinkel. Regulation of the peripheral metabolism of the thyroid hormones. Recent Progr. Hormone Res. 1960, 16, 353.

20. Robbins, J., and J. E. Rall. Proteins associated with the thyroid hormones. Physiol. Rev. 1960, 40, 415.

21. Woeber, K. A., and S. H. Ingbar. The effects of noncalorigenic congeners of salicylate on the peripheral metabolism of thyroxine. J. clin. Invest. 1964, 43, 931.

22. Oppenheimer, J. H., R. Squef, M. I. Surks, and H. Hauer. Binding of thyroxine by serum proteins evaluated by equilibrium dialysis and electrophoretic techniques: Alterations in non-thyroidal illness. J. clin. Invest. 1963, 42, 1769.

23. Surks, M. I., and J. H. Oppenheimer. Postoperative changes in the concentration of thyroxine-binding prealbumin and serum free thyroxine. J. clin. Endocr. 1964, 24, 794.
24. Ingbar, S. H., L. E. Braverman, N. A. Dawber, and G. Y. Lee. A new method for measuring the free thyroid hormone in human serum and an analysis of the factors that influence its concentration. $\mathrm{J}$. clin. Invest. 1965, 44, 1679.

25. Bernstein, G., and J. H. Oppenheimer. Factors influencing the concentration of free and total thyroxine in patients with nonthyroidal disease. $J$. clin. Endocr. 1966, 26, 195.

26. Hollander, C. S., R. L. Scott, C. G. McKerron, and S. P. Asper. Plasma free fatty acids: A possible regulator of free thyroid hormone level in man. (abstract) Clin. Res. 1967, 15, 259.

27. Oppenheimer, J. H., G. Bernstein, J. Hasen, and C. H. Sutton. Determination and kinetic significance of the exchangeable intracellular thyroxine pool in man. (abstract) J. clin. Invest. 1966, 45, 1054.

28. Oppenheimer, J. H., G. Bernstein, and J. Hasen. Estimation of rapidly exchangeable cellular thyroxine from the plasma disappearance curves of simultaneously administered thyroxine ${ }^{131} \mathrm{I}$ and albumin- ${ }^{125}$ I. J. clin. Invest. 1967, 46, 762.

\section{NOTICE TO SUBSCRIBERS}

Post Offices will not forward the Journal when you move.

Please notify The Journal of Cinical Investigation, The Rockefeller University Press, Box 261, New York, N. Y. 10021, when your address changes. Include your zip code number. 